\title{
RKIP and peroxiredoxin 2 expression predicts the proliferative potential of gastric cancer stem cells
}

\author{
SHAO-FENG YANG, RAN MA, LI-LI PAN, JING CAO and NAN SHENG \\ Department of Gastroenterology, Jining First People's Hospital, Jining, Shandong 272011, P.R. China
}

Received May 27, 2016; Accepted April 25, 2017

DOI: $10.3892 / 01.2017 .7700$

\begin{abstract}
Gastric cancer is associated with a high mortality rate, with the development of gastric cancer stem cells underlying this. Gastric cancer stem cells are responsible for tumor initiation, progression and recurrence. However, the link between gastric cancer and gastric cancer stem cells remains to be fully understood. Murine models mimic a human microenvironment more accurately than in vitro studies and are useful models for understanding the behavior of different markers. The present study compared the expression of cluster of differentiation 44 (CD44), a stem cell marker, with the expression of other cancer-associated markers, including Raf kinase inhibitor protein (RKIP) and peroxiredoxin 2, in different pathological conditions of gastric cancer development using histological, immunohistological and western blot analyses. Initially, the murine model of gastric cancer was established using N-methyl-N-nitrosourea, a chemical carcinogen. Following initiation of cancer, immunohistochemistry was used to compare the expression of CD44, RKIP and peroxiredoxin 2 at different stages of cancer development. The results suggested CD44 and peroxiredoxin 2 expression was upregulated as the tumor progressed. However, expression of RKIP, a metastasis suppressor, was elevated in the initial stage of gastric cancer and suppressed during the aggressive stages. In agreement with previous data suggesting higher expressions of RKIP in the initial stages of cancer and its downregulation in the advanced stage, the results of the present study revealed that RKIP exhibited a negative effect on initial tumor development, and that the downregulation of RKIP in the advanced stages of cancer facilitated CD44 and peroxiredoxin 2 overexpression.
\end{abstract}

Correspondence to: Dr Nan Sheng, Department of Gastroenterology, Jining First People's Hospital, 6 Jiankang Road, Jining, Shandong 272011, P.R. China

E-mail: shengnan32@hotmail.com

Key words: cluster of differentiation 44, peroxiredoxin 2, Raf kinase inhibitor protein, $\mathrm{N}$-methyl-N-nitrosourea

\section{Introduction}

Gastric cancer is the fourth most common cancer globally and was the second-highest cause of cancer-associated mortality in 2014 (1-4). Although various factors are implicated in gastric cancer development, the underlying mechanisms remain unclear (5). Cancer stem cells serve a key function in gastric tumor initiation, metastasis and recurrence (6). Treatment procedures that eliminate gastric cancer stem cells may improve longevity as well as increase the cure rate (7-9). Identifying gastric cancer in the early stages may help prevent gastric cancer progression. Understanding how cancer stem cells are involved in the mechanisms underlying cancer invasion and recurrence is vital in overcoming treatment failure.

The molecular markers that identify gastric cancer stem cells are useful in understanding the pathogenic nature of gastric cancer. Gastric cancer stem cells are derived from stem cells of gastric origin (10-12). Such cells have tumor-propagating properties but are difficult to identify in different pathological stages of cancer due to their phenotypic similarities in comparison with non-cancerous stem cells, yet certain cell surface marker including CD44 are used to identify them (13). Raf kinase inhibitor protein (RKIP) acts as a metastasis suppressor by inhibiting multiple cell survival mechanisms and thereby inducing apoptosis $(14,15)$ in multiple types of cancer, including colon, prostate and breast cancers and melanoma (16-19). However, the function of RKIP in the development of gastric cancer stem cells and cancer progression remains to be fully understood. Peroxiredoxins are a group of enzymes that act as antioxidants and exert control over tumor development (20). As cancer develops, cancer cells develop resistance against apoptosis-inducing oxidative damage (21). However, the function of peroxiredoxins in carcinogenesis, in particular the activity of peroxiredoxins in cancer stem cells, remains to be fully understood. Using a murine gastric cancer model, the present study examined the expression of RKIP and peroxiredoxin 2 in gastric cancer stem cells.

\section{Materials and methods}

Experimental animals. Male BALB/c (The Jackson Laboratory, Wuhan, China; age, 3 months; weight, 25-28 g) mice were used in the present study. Each group comprised 6 mice, maintained in controlled conditions (temperature, $26-28^{\circ} \mathrm{C}$; humidity, 
50-60\%) and fed ad libitum. The present study and protocols were approved by the Animal Care and Ethical Committee of Jining First People's Hospital (Jinning, China). To induce gastric cancer, the chemical carcinogen N-methyl-N-nitrosourea (MNU) was provided with drinking water at a concentration of 200 ppm. Following daily intake of MNU, the mice developed initial tumors by week 4 and developed aggressive tumors by week 8 , as determined by histological analysis. MNU is a standard protocol for developing murine gastric cancer $(22,23)$. Following tumor development, initial and aggressive tumor samples were collected from mice sacrificed at weeks 4 and 8 , respectively, and samples (4-12 $\mathrm{mm}$ size) from control mice, initial and aggressive tumor tissues were collected. A total of 6 mice were sacrificed at week 4 , and the remaining mice at week 8 . Humane end-points were set at a loss of 3-5 g body weight in mice with initial tumors, and a loss of up to 8 in mice with aggressive tumors. The tumors ranged in size, with initial and aggressive tumors measuring between 4-6 and 8-12 mm, respectively.

Histological analysis and immunohistochemistry. To perform histological and immunohistochemical analysis, tissues were initially fixed in a $10 \%$ formaldehyde fixative solution at room temperature for $48 \mathrm{~h}$. Tissues were then embedded in paraffin for sectioning. Using a microtome, the paraffin-embedded tissues were sliced into $6 \mu \mathrm{m}$ sections. The sections were then placed on glass slides and deparaffinized by heating in a slide warming table at $70^{\circ} \mathrm{C}$ for $5 \mathrm{~min}$. The slides were then immersed in xylene to remove wax and subsequently immersed in alcohol solution and then rehydrated with distilled water. To observe histological alterations, the slides were stained with hematoxylin (catalog no., HHS16; Sigma-Aldrich; Merck KGaA, Darmstadt, Germany) for $7 \mathrm{~min}$ and eosin (catalog no., HT110132; Sigma-Aldrich; Merck KGaA) for $30 \mathrm{sec}$ at room temperature and visualized under the light microscope at x20 magnification (Eclipse Ti2, Nikon, Tokyo, Japan). For immunohistochemistry, the processed slides were immersed in $0.3 \% \mathrm{H}_{2} \mathrm{O}_{2}$ in $1 \mathrm{X}$ PBS for $15 \mathrm{~min}$ at room temperature to block endogenous peroxidase activity. The sections were then incubated with $4 \%$ bovine serum albumin (BSA; catalog no., A6003; Sigma-Aldrich; Merck KGaA) blocking buffer in PBS for $1 \mathrm{~h}$ at room temperature and further incubated with anti-RKIP antibody (cat. no., epr2875Y; GeneTex, Inc., Irvine, CA, USA; 1:400 dilution), anti-peroxiredoxin 2 antibody (cat. no., ab71533; Abcam, Cambridge, UK; 1:250 dilution) or anti-cluster of differentiation 44 (CD44) antibody (cat. no., ab51037; Abcam; 1:300 dilution) overnight at $4^{\circ} \mathrm{C}$. Following washing with $1 \mathrm{X}$ TBST, the slides were incubated with the horseradish peroxidase-conjugated anti-rabbit IgG (cat. no., ab6721; Abcam; 1:2,000 dilution) for $30 \mathrm{~min}$ at room temperature. 3,3'-diaminobenzidine solution (5 mg in $10 \mathrm{ml}$ ) was subsequently applied to stain the antibody binding site. Following staining, the slides were visualized under the light microscope (Eclipse Ti2, Nikon, Tokyo, Japan) and the images were captured under magnification, $\mathrm{x} 20$.

Western blot analysis. Protein samples were prepared by homogenizing the tissue samples in $2 \mathrm{X}$ protein sample buffer (2 ml Tris (1 M, pH 6.8), $4.6 \mathrm{ml}$ glycerol (50\%), $1.6 \mathrm{ml}$ SDS (10\%), $0.4 \mathrm{ml}$ bromophenol blue $(0.5 \%)$ and $0.4 \mathrm{ml}$ $\beta$-mercaptoethanol) on ice to release the cell lysates from control, initial tumor and aggressive gastric cancer tissues. The prepared samples were immediately heated in a boiling water bath for $5 \mathrm{~min}$ and allowed to cool. The concentration of protein present in each sample were estimated by Lowry method (24). The present study used the same method for performing western blot analysis as a previous study (25). The cell lysate with $70 \mu \mathrm{g}$ protein was separated using $12 \%$ SDS-PAGE. Once the gel was run to the bottom, the separated proteins were transferred to a polyvinylidene fluoride membrane. The membrane was subsequently blocked at room temperature for $2 \mathrm{~h}$ using $4 \% \mathrm{BSA}$ in $1 \mathrm{X}$ TBST to prevent non-specific binding and additionally incubated with anti-RKIP antibody (cat. no., epr2875Y; GeneTex, Inc; 1:1,000 dilution), anti-peroxiredoxin 2 antibody (cat. no., ab71533; Abcam; 1:2,000 dilution) or anti-CD44 antibody (cat. no., ab51037; Abcam; 1:4,000 dilution) overnight at $4^{\circ} \mathrm{C}$. Tubulin antibody (cat. no., Ab6046; Abcam; 1:500 dilution) was used for the control. Following washing with $1 \mathrm{X}$ TBST, the membrane was incubated with alkaline phosphatase-conjugated anti-Rabbit IgG; cat. no., ab97048; Abcam; $1: 3,000)$ for $1 \mathrm{~h}$ at room temperature to identify the binding of the primary antibodies. Following two additional washes with $1 \mathrm{X}$ TBST solution, the membrane was developed with 5-Bromo-4-chloro-3-indolyl phosphate/Nitro blue tetrazolium (catalog no., B1911; Sigma Aldrich; Merck KGaA) to obtain the signal.

\section{Results}

In vivo mice model for gastric cancer. In vitro models using gastric cancer cell lines have certain disadvantages as the responses of the cells and the associated carcinogenic mechanisms differ among different cell lines and compared with in vivo models. Therefore, an animal model that mimics human microenvironments is essential for understanding the different stages of gastric cancer $(26,27)$. A murine gastric cancer model was established using the carcinogen MNU. MNU induced the first gastric tumors in week 4 and resulted in an aggressive form of gastric cancer in week 8, which are observed through histological complication of tissue sections $(6 \mu \mathrm{m})$ that are observed with hematoxylin and eosin staining (Fig. 1). The control gastric tissue was uniform in pattern, with loosely packed cells (Fig. 1A). Following MNU intake, mice developed initial tumors in week 4; the histological section revealed a proliferative mass of cells with increased cell density (Fig. 1B) when compared with control. As the tumor developed to an aggressive form in week 8, the histological section revealed a clustering of cellular patterns with large, elongated nuclei (Fig. 1C).

CD44 expression and its association with gastric cancer stem cells. CD44 expression is associated with the extracellular matrix. CD44 acts as an adhesion molecule that determines cell proliferation and cell survival $(28,29)$. CD44 expression is associated with gastric cancer stem cell development (30). In the present study, CD44 was used as a standard marker for gastric cancer stem cells to determine the key function 
A

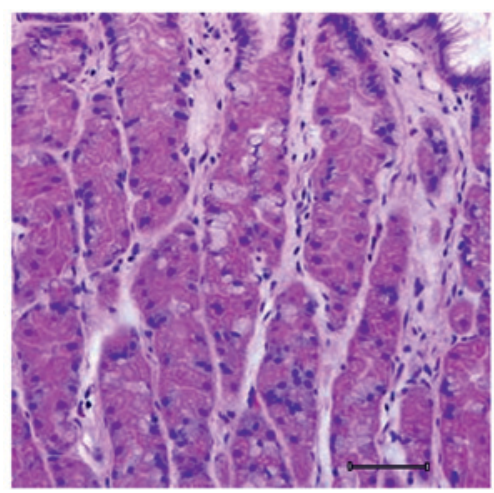

B

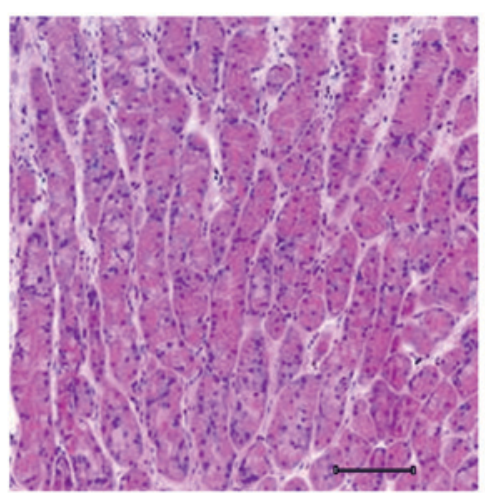

$\mathrm{C}$

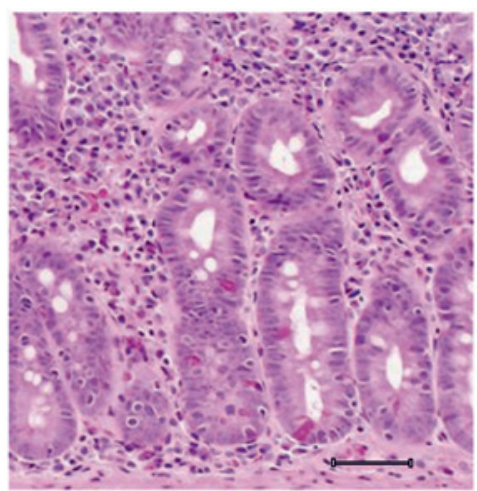

Figure 1. Murine model of gastric cancer. (A) Control gastric tissue exhibiting regular pattern of cell arrangement. (B) Gastric cancer tissue in initial stages with modest cell mass ratio. (C) Aggressive gastric cancer tissue with intense cell proliferation (hematoxylin \& eosin; scale bar=100 $\mu \mathrm{m}$ ).

A

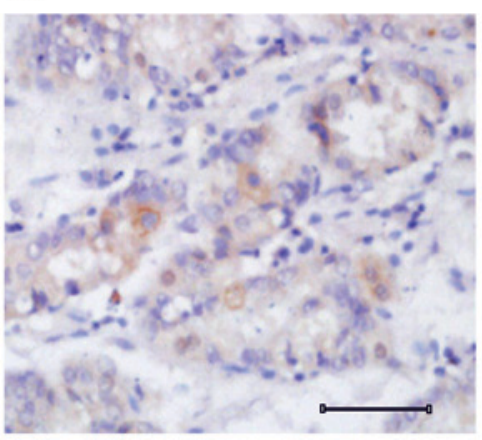

D

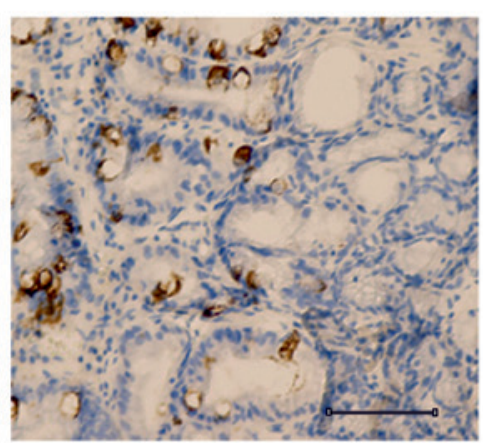

G

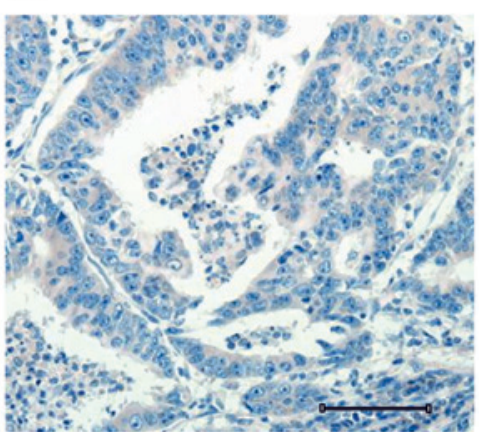

B

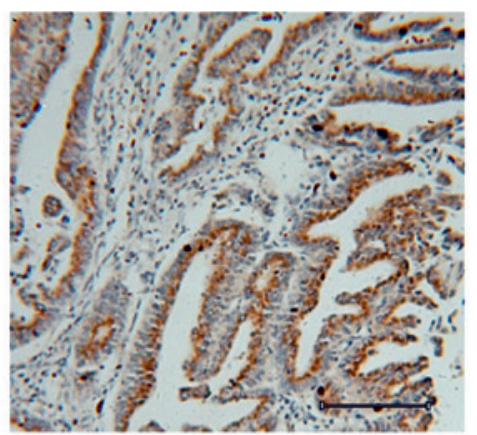

E

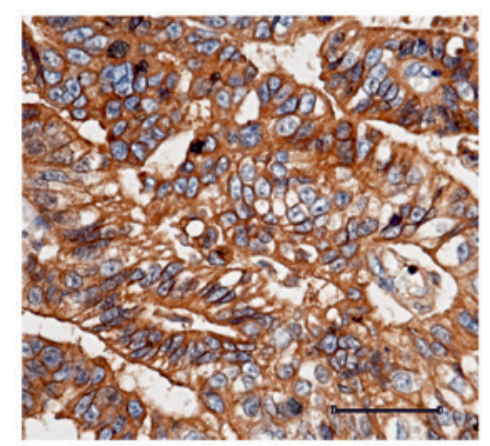

H

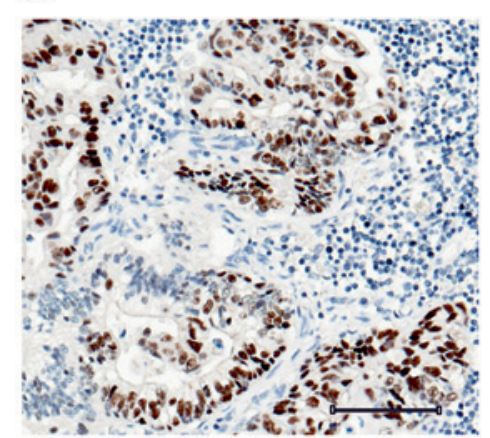

C

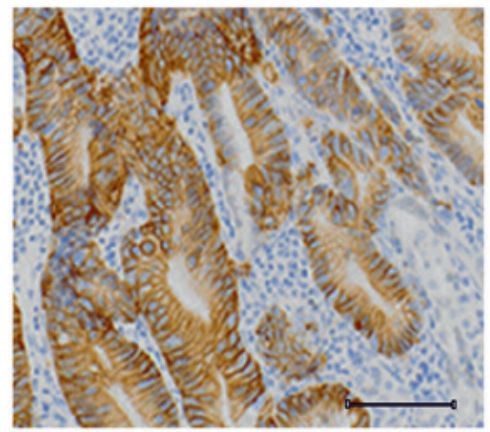

F

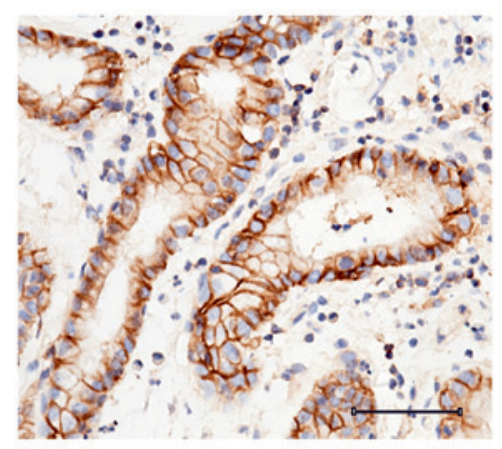

I

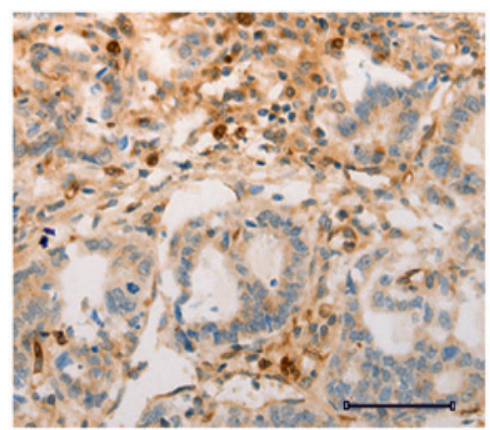

Figure 2. Comparative analysis of CD44, RKIP and peroxiredoxin 2 expression in different stages of gastric cancer. (A) CD44 exhibiting low expression in normal control tissue. (B) Initial gastric tumor tissue with increased expression of CD44. (C) Aggressive gastric tumor tissue exhibiting further increased expression of CD44. (D) Normal control gastric tissue exhibiting moderate RKIP expression. (E) Initial stage of gastric cancer with increased expression of RKIP. (F) Aggressive stage of gastric cancer with decreased expression of RKIP compared with initial tissue. (G) Normal control gastric tissue with low expression of peroxiredoxin 2 compared with tumor tissues. (H) Low-grade gastric tumor exhibiting increased expression of peroxiredoxin 2 compared with normal control tissue. (I) High-grade tumor exhibiting increased expression of peroxiredoxin 2 compared with initial tumor tissue. (Scale bar=100 $\mu \mathrm{m}$ ). CD44, cluster of differentiation 44; RKIP, Raf kinase inhibitor protein. 


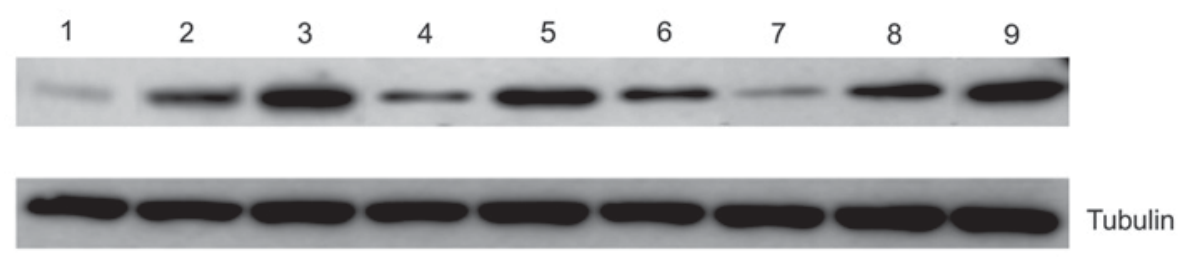

Figure 3. Western blot analysis. Lane 1 represents CD44 expression in normal control gastric tissue. Lane 2 represents CD44 expression in initial gastric tumors. Lane 3 represents CD44 expression in aggressive gastric tumors. Lane 4 represents RKIP expression in normal control gastric tissue. Lane 5 represents increased RKIP expression in initial gastric tumors in comparison with control tissues. Lane 6 represents RKIP expression in aggressive gastric tumors. Lane 7 represents peroxiredoxin 2 expression in normal control gastric tissue. Lane 8 represents peroxiredoxin 2 expression in low-grade gastric tumors. Lane 9 represents peroxiredoxin 2 expression in high-grade gastric tumors. Tubulin was used as a loading control. CD44, cluster of differentiation 44; RKIP, Raf kinase inhibitor protein.

of RKIP and peroxiredoxin 2 in gastric cancer stem cells. Immunohistochemical analysis was used to examine the expression pattern of CD44 in control, initial and aggressive gastric cancer tissue samples. The control tissue revealed diluted expression of the CD44+ cells that were spread over the tissue layer (Fig. 2A). The transition of normal tissue to initial gastric cancer tissue in week 4 was associated with increased expression of CD44 (Fig. 2B). The transition of initial gastric cancer tissue to aggressive gastric cancer tissue in week 8 was associated with an additional increase in CD44 expression (Fig. 2C).

Comparative analysis of CD44, RKIP and peroxiredoxin 2 expressions. RKIP acts as a metastasis suppressor and regulates tumor progression (31). The present study comparatively analyzed CD44, RKIP and peroxiredoxin 2 expression to elucidate their functions in gastric tumor regulation. The expression pattern of RKIP was analyzed in non-cancerous tissue and revealed similar expression to CD44 (Fig. 2D). However, the increase of RKIP expression in initial cancer tissue compared with control tissue was greater compared with the increase in CD44 (Fig. 2E). The results suggested that RKIP initially functions as a tumor suppressor, and is able to exert control over tumor progression. However, RKIP expression was decreased in the aggressive stage of tumor development to levels comparable to the control tissue (Fig. 2F). Similarly, peroxiredoxin 2expression was analyzed and was revealed to be sequentially upregulated as the tumor progressed from normal tissue to initial cancer tissue to aggressive cancer tissue (Fig. 2G-I). The control tissue revealed low expression of peroxiredoxin 2 (Fig. 2G), while the initial cancer tissue revealed increased expression compared with the control (Fig. 2H). The aggressive cancer tissue exhibited an additional increase in peroxiredoxin 2 expression.

Western blotting analysis. The data obtained using immunohistochemical analysis were further validated using western blotting analysis. The results of western blotting determined that expression of CD44 (Fig. 3; lane 1-3) and peroxiredoxin 2 increased with tumor progression (Fig. 3; lane 7-9). Immunohistochemical analysis revealed that RKIP was overexpressed in initial gastric cancer tissue compared with control tissue, but expression was decreased in aggressive gastric cancer tissue compared with initial cancer tissue (Fig. 3; lane 4-6).

\section{Discussion}

The study of stem cell markers at different pathological stages remains challenging due to changes in marker expression profiles. Identifying novel stem cell markers may assist in improving the understanding of how tumors progress and the mechanisms by which tumors are initiated (32). The present study used CD44, a well-studied tumor marker associated with gastric cancer stem cells (13). CD44 was used to assess the expression patterns of RKIP and peroxiredoxin 2 under different pathological conditions.

Previous studies have suggested that peroxiredoxin 2 expression decreases in certain types of cancer tissue and increases in others. For example, certain studies have demonstrated that peroxiredoxin 2 expression decreases in lung cancer tissue when compared with control tissues (31), while others reported that peroxiredoxin 2 expression increases in other types of human cancers (34). Therefore, the results concerning peroxiredoxin 2 expression in the present study require further examination. In addition, the gastric cancer model was successfully established in the BALB/c mice used in the present study, and demonstrated pathological conditions similar to human gastric cancer models (35).

The histological results also assisted in understanding how the tumors progressed as the mice continued to be treated with MNU (Fig. 1A-C). Similarly, the tumor progression assisted in understanding the expression patterns of different protein markers. Comparative immunohistochemical analysis suggested CD44 and RKIP expressions influenced gastric tumor development. The present study suggested that RKIP negatively regulated initial tumor development and exerted less control over tumor development in the aggressive stage, during which CD44 expression increased (Fig 2A-F). While the present study supported the previously reported mechanism of tumor metastasis suppression by RKIP (34), this mechanism was observed only in the initial tumor stage. The present study demonstrated that peroxiredoxin 2 expression was upregulated as gastric tumors progressed (Fig. 2G-I) and exhibits a similar linear expression pattern to CD44.

In summary, the present study successfully established a murine gastric cancer model using the chemical carcinogen MNU, and comparatively analyzed the expression patterns of CD44, RKIP and peroxiredoxin 2 during gastric cancer stem cell expansion, potentially assisting to inform the design of novel therapeutic interventions in gastric cancer. 


\section{References}

1. Parkin DM, Bray F, Ferlay J and Pisani P: Global cancer statistics, 2002. CA Cancer J Clin 55: 74-108, 2005.

2. Ferlay J, Shin HR, Bray F, Forman D, Mathers C and Parkin DM: Estimates of worldwide burden of cancer in 2008: GLOBOCAN 2008. Int J Cancer 127: 2893-2917, 2010.

3. Siegel R, Ward E, Brawley O and Jemal A: Cancer statistic, 2011: The impact of eliminating socioeconomic and racial disparities on premature cancer deaths. Ca Cancer J Clin 61: 212-236, 2011

4. DeSantis CE,Lin CC, Mariotto AB, Siegel RL, Stein KD, Kramer JL, Alteri R, Robbins AS and Jemal A: Cancer treatment and survivorship statistics, 2014. CA Cancer J Clin 64: 252-271, 2014.

5. Singh SR: Gastric cancer stem cells: A novel therapeutic target. Cancer Lett 338: 110-119, 2013.

6. Zhao Y, Feng F and Zhou YN: Stem cells in gastric cancer. World J Gastroenterol 21: 112-123, 2015.

7. Roboz GJ and Guzman M: Acute myeloid leukemia stem cells: Seek and destroy. Expert Rev Hematol 2: 663-672, 2009.

8. Valent P: Targeting of leukemia-initiating cells to develop curative drug therapies: Straightforward but nontrivial concept Current Cancer Drug Targets 11: 56-71, 2011.

9. Korkaya $\mathrm{H}$ and Wicha MS: Selective targeting of cancer stem cells. BioDrugs 21: 299-310, 2007.

10. Zhu L, Gibson P, Currle DS, Tong Y, Richardson RJ, Bayazitov IT, Poppleton H, Zakharenko S, Ellison DW and Gilbertson RJ: Prominin 1 marks intestinal stem cells that are susceptible to neoplastic transformation. Nature 457: 603-607, 2009.

11. Barker N, Ridgway RA, Van Es JH, van de Wetering M, Begthel H, van den Born M, Danenberg E, Clarke AR, Sansom OJ and Clevers H: Crypt stem cells as the cells-of-origin of intestinal cancer. Nature 457: 608-611, 2009

12. Cozzio A, Passegué E, Ayton PM, Karsunky H, Cleary ML and Weissman IL: Similar MLL-associated leukemias arising from self-renewing stem cells and short-lived myeloid progenitors. Genes Dev 17: 3029-3035, 2003.

13. Yeung K, Seitz T, Li S, Janosch P, McFerran B, Kaiser C, Fee F, Katsanakis KD, Rose DW, Mischak H, et al: Suppression of Rafkinase activity and MAP kinase signalling by RKIP. nature 401: 173-177, 1999.

14. Chatterjee D, Bai Y, Wang Z, Beach S, Mott S, Roy R, Braastad C, Sun Y, Mukhopadhyay A and Aggarwal BB: RKIP sensitizes prostate and breast cancer cells to drug-induced apoptosis. J Biol Chem 279: 17515-17523, 2004.

15. Al-Mulla F, Hagan S, Behbehani AI, Bitar MS, George SS Going JJ, García JJ, Scott L, Fyfe N, Murray GI and Kolch W: Raf kinase inhibitor protein expression in a survival analysis of colorectal cancer patients. J Clin Oncol 24: 5672-5679, 2006.

16. Keller ET, Fu Z, Yeung K and Brennan M: Raf kinase inhibitor protein: A prostate cancer metastasis suppressor gene. Cancer Lett 207: 131-137, 2004

17. Hagan S, Al-Mulla F, Mallon E, Oien K, Ferrier R, Gusterson B, García JJ and Kolch W: Reduction of Raf-1 kinase inhibitor protein expression correlates with breast cancer metastasis. Clin Cancer Res 11: 7392-7397, 2005.

18. Schuierer MM, Bataille F, Hagan S, Kolch W and Bosserhoff A-K Reduction in Raf kinase inhibitor protein expression is associated with increased Ras-extracellular signal-regulated kinase signaling in melanoma cell lines. Cancer Res 64: 5186-5192, 2004.
19. Nyström T, Yang J and Molin M: Peroxiredoxins, gerontogenes linking aging to genome instability and cancer. Genes Dev 26: 2001-2008, 2012 .

20. Szatrowski TP and Nathan CF: Production of large amounts of hydrogen peroxide by human tumor cells. Cancer Res 51 794-798, 1991

21. Yamamoto M, Furihata C, Ogiu T, Tsukamoto T, Inada Ki, Hirano $\mathrm{K}$ and Tatematsu $\mathrm{M}$ : Independent variation in susceptibilities of six different mouse strains to induction of pepsinogen-altered pyloric glands and gastric tumor intestinalization by N-methyl-N-nitrosourea. Cancer Lett 179: 121-132, 2002.

22. Hayakawa Y, Fox JG, Gonda T, Worthley DL, Muthupalani S and Wang TC: Mouse models of gastric cancer. Cancers (Basel) 5: 92-130, 2013

23. Hamidouche Z, Haÿ E, Vaudin P, Charbord P, Schüle R, Marie PJ and Fromigué O: FHL2 mediates dexamethasone-induced mesenchymal cell differentiation into osteoblasts by activating Wnt/beta-catenin signaling-dependent Runx2 expression. FASEB J 22: 3813-3822, 2008

24. Waterborg JH: The Lowry method for protein quantitation. protein Protoc Handb: 7-9, 2002.

25. Abate-Shen C: Deregulated homeobox gene expression in cancer: Cause or consequence? Nat Re Cancer 2: 777-785, 2002.

26. Yu S, Yang M and Nam KT: Mouse models of gastric carcinogenesis. J Gastric Cancer 14: 67-86, 2014

27. Jang BI, Li Y, Graham DY and Cen P: The role of CD44 in the pathogenesis, diagnosis and therapy of gastric cancer. Gut Liver 5: 397-405, 2011.

28. Ghaffarzadehgan K, Jafarzadeh M, Raziee HR, Sima HR, Esmaili-Shandiz E, Hosseinnezhad H, Taghizadeh-Kermani A, Moaven $\mathrm{O}$ and Bahrani M: Expression of cell adhesion molecule CD44 in gastric adenocarcinoma and its prognostic importance. World J Gastroenterol 14: 6376-6381, 2008.

29. Nosrati A, Naghshvar F and Khanari S: Cancer stem cell markers CD44, CD133 in primary gastric adenocarcinoma. Int J Mol Cell Med 3: 279-286, 2014

30. Li X, Wang J, Xu Z, Ahmad A, Li E, Wang Y, Qin S and Wang Q: Expression of sox 2 and oct 4 and their clinical significance in human non-small-cell lung cancer. Int J Mol Sci 13: 7663-7675, 2012.

31. Park YH, Kim SU, Lee BK, Kim HS, Song IS, Shin HJ, Han YH, Chang KT, Kim JM, Lee DS, et al: Prx I suppresses K-ras-driven lung tumorigenesis by opposing redox-sensitive ERK/cyclin D1 pathway. Antioxid Redox Signal 19: 482-496, 2013.

32. Diao S, Zhang Jf, Wang H, He ML, Lin MC, Chen $Y$ and Kung HF: Proteomic identification of microRNA-122a target proteins in hepatocellular carcinoma. Proteomics 10: 3723-3731, 2010.

33. Takaishi S, Okumura T, Tu S, Wang SS, Shibata W, Vigneshwaran R, Gordon SA, Shimada Y and Wang TC: Identification of gastric cancer stem cells using the cell surface marker CD44. Stem Cells 27: 1006-1020, 2009.

34. Beshir AB, Ren G, Magpusao AN, Barone LM, Yeung KC and Fenteany G: Raf kinase inhibitor protein suppresses nuclear factor- $\kappa \mathrm{B}$-dependent cancer cell invasion through negative regulation of matrix metalloproteinase expression. Cancer Lett 299: 137-149, 2010.

35. Jin DZ, Jung HC, Kim JM, Kim JS, Song IS and Kim CY: Establishment of BALB/c mice model infected with Helicobacter pylori. Korean J Intern Med 14: 55-63, 1999. 